\title{
Informações socioambientais de relatórios empresariais - legislação colombiana e normatização brasileira
}

\author{
Iliana de Los Ángeles Pachón Bolaños* \\ Bruna ANDRAde Matos** \\ Carina de Farias Gonçalves***
}

Brasil

\section{Introdução}

Os problemas ambientais e sociais do presente evidenciam a necessidade crescente de buscar formas mais sustentáveis para atender às necessidades da geração atual e da futura, garantindo o bem-estar social de todos. Isso é o que define o Relatório de Brundtland, Our Common Future, da World Commission on Environment and Development (1987), acerca do desenvolvimento sustentável (DS).

Diante de tal cenário, as empresas têm sido cobradas a contribuírem para um mundo mais justo e sustentável, a adotarem ações que tenham como base a promoção do bem-estar social. Dessa forma, o DS tornou-se um conceito de gestão de grande valor no setor corporativo,

* Bacharel em ciências contábeis. Corporación Universitaria Minuto de Dios (Uniminuto), Regional Pereira, Colômbia.nanitapachon@gmail.com

** Bacharel em ciências contábeis. Universidade Estadual de Santa Cruz (UESC), Brasil.bruna.matoss@yahoo.com.br

***Doutoranda em desenvolvimento e meio ambiente. Universidade Estadual de Santa Cruz (uesc), Brasil. Docente de ciências contábeis. afgoncalves@uesc.br 
uma vez que uma empresa socialmente responsável consegue ter maior prestígio perante seus usuários.

Relatórios sociais são divulgados anualmente por empresas comprometidas a evidenciar suas práticas sociais e ambientais. Nesses documentos, constam informações gerais e específicas de diversas ações e metas expostas em números e textos. Atualmente, o Balanço Social e o Relatório de Sustentabilidade são os modelos mais utilizados pelas empresas, sendo o segundo o mais encontrado por ser mais abrangente e flexível quanto ao conteúdo exposto (Becchetti, Ciciretti, Hasan \& Kobeissi, 2012).

Além da criação de normas para a construção e a divulgação de relatórios sociais, as últimas décadas foram marcadas por acréscimos e alterações na legislação de cada país com vistas a atender à demanda das questões sociais e ambientais em curso. Seja com acordos mundiais por intermediações com a Organização das Nações Unidas (ONU), seja por iniciativa própria (Vasconcelos, 2011).

Esta pesquisa foi realizada na Empresa Colombiana de Petróleo (Ecopetrol), a maior empresa do ramo nesse país. Dada a relevância da temática, pretendeu responder aos seguintes questionamentos: a legislação colombiana vigente atende às necessidades atuais com relação à divulgação de práticas socialmente responsáveis por parte das empresas? O relatório de sustentabilidade da Ecopetrol evidencia com transparência suas práticas sociais e ambientais aos seus usuários? Como a ciência contábil pode auxiliar no processo de incentivo e divulgação das práticas sustentáveis empresariais a partir de normatizações específicas como o caso brasileiro da NBC T 15 ?

Dessa forma, o objetivo do trabalho foi avaliar o relatório integrado de gestão sustentável da empresa Ecopetrol (2014) quanto à transparência das informações, com base na legislação colombiana pertinente em comparação à normatização contábil brasileira (NBC T 15), identificando sinergias e visando demonstrar a relevância da contabilidade socioambiental no incentivo e na divulgação de práticas empresariais socialmente responsáveis. 


\section{Fundamentação teórica}

A responsabilidade social é aplicada a todos os tipos e portes de organizações e deve ser uma mentalidade proativa incorporada em todos os níveis de planejamento, execução e interação das partes interessadas (ABNT NBR Iso 26000, 2010).

Até recentemente, o conceito de responsabilidade social confundiase com filantropia, ou seja, ações caridosas que as empresas realizavam voluntariamente. Isso porque se acreditava que somente o Estado, os governos e suas instituições tinham obrigações ante a sociedade e o meio ambiente (Eon, 2015).

A definição cunhada pela norma internacional e adotada pela Associação Brasileira de Normas Técnicas (ABNT NBR 16001, 2012) é a de que a empresa seja responsável pelos impactos de suas decisões e atividades na sociedade e no meio ambiente, por meio do comportamento ético e transparente que:

- contribua para o desenvolvimento sustentável, inclusive para a saúde e o bem-estar da sociedade;

- leve em consideração as expectativas das partes interessadas;

- esteja em conformidade com a legislação aplicável;

- seja consistente com as normas internacionais de comportamento, e

- esteja integrada em toda a organização e seja praticada em suas relações.

Os Estados Unidos e a Europa foram os pioneiros em cobrar das empresas maior responsabilidade social a partir da publicação de relatórios sociais. A consolidação dessa necessidade e cobrança deu-se a partir da década de 1960 (Torres, 2001). Na França, desde 1977, existe a Lei de Responsabilidade Social que obriga as empresas a publicarem o Balanço Social (Becchetti et al., 2012).

No Brasil, desde 1997, o falecido sociólogo Herbert de Souza (Betinho) e o Instituto Brasileiro de Análises Sociais e Econômicas (Ibase) chamaram a atenção dos empresários e de toda a sociedade para a importância e a necessidade da publicação dessa demonstração a fim 
de evidenciar as informações de caráter social (Vieira \& Faria, 2007; Vellani, 2011).

No relatório de sustentabilidade, a empresa pode contar toda a história sustentável da empresa, junto com os dados em números orientados pela Norma Brasileira de Contabilidade NBC т 15. No caso do Balanço Social, são encontrados apenas os dados, dispostos em tabelas, o que às vezes pode não conter todas as informações desejadas pelas empresas.

O Conselho Federal de Contabilidade (CFC) manifestou interesse sobre o assunto por meio das Normas Brasileiras de Contabilidade, com a Resolução CFC n. ${ }^{\circ}$ 1.003/2004, aprovando a NBC T 15 - Informações de natureza social e ambiental. Essas normas entraram em vigor em $1^{\circ}$ de janeiro de 2006. Segundo a NBC T 15, a demonstração de informações de natureza social e ambiental deve evidenciar os dados e informações da entidade dessa natureza, extraídas ou não da contabilidade (CFC, 2004).

Pontos negativos também são levantados por indicadores diversos, que, supostamente, expõem falhas da empresa. No entanto, vale ressaltar a necessidade dessas abordagens, uma vez que se trata de um balanço e, portanto, deve-se considerar informações de efeitos positivos e negativos, assim como os direitos e as obrigações apresentados no Balanço Patrimonial (Dowbor, Sachs \& Lopes, 2010). Nesse quesito, mais uma vez, a NBC T 15 recebe destaque ao requerer tais indicadores em seu modelo.

Por fim, outros fatores a serem observados em um relatório social sob o modelo da NBC T 15 consistem na presença de notas explicativas, identificação do responsável pela geração das informações divulgadas e auditoria externa. Tais itens representam maior confiabilidade e transparência a toda e qualquer demonstração.

Siqueira e Vidal (2002) realizaram um estudo nos balanços sociais publicados por 21 empresas em 2001, nos quais apenas seis apresentaram notas explicativas. Beets e Souther (1999) já criticavam a transparência desses relatórios devido ao baixo nível de complexidade das informações prestadas nas escassas notas explicativas.

A NBC T 15, porém, incentiva o uso de notas explicativas e dispõe, no item 15.3.1, que "além das informações contidas no item 15.2 
(informações a serem divulgadas), a entidade pode acrescentar ou detalhar outras que julgar relevantes" (CFC, 2004). Em seu item seguinte, o 15.3.2, a norma aborda a questão da identificação do responsável. Em suma, a NBC T 15 define-se como a norma mais completa e abrangente do país, com maior número de indicadores, clareza e fornecimento de subsídios para maior comparabilidade. No entanto, não inclui “[...] sanções quanto ao seu descumprimento" (Carvalho \& Siqueira, 2012, p. 38).

No contexto colombiano, tem-se a legislação ambiental pertinente, que foi constituída pelas regras que possibilitam a relação entre o homem e o meio ambiente, e foi criada em 1913 com a lei sobre a proteção das florestas. Em 1973, a Lei Marco, que autoriza a emissão do Código de Recursos Naturais, estabeleceu que o ambiente é patrimônio comum da população.

Então, em 1991, como resultado da nova Constituição Política Colombiana, o conceito de proteção ao meio ambiente foi redimensionado e elevou-se à categoria dos direitos coletivos, promovendo mecanismos de proteção por parte dos cidadãos. Mais tarde, a Lei 99 de 1993, a partir da qual foi criada a Secretaria do Meio Ambiente, reorganizou o setor público responsável pela gestão e pela conservação do meio ambiente e dos recursos renováveis, criou o Sistema Nacional do Meio Ambiente (Sina) e também as Corporações Autônomas Regionais (CARs).

No ano seguinte ao da criação da Lei supracitada, promulgou-se o Decreto 1.753/1994 a fim de estudar o impacto ambiental, bem como para ser utilizado como ferramenta na tomada de decisão e no planejamento ambiental necessários para definir a prevenção, correção, compensação e mitigação de impactos negativos de um projeto ou atividade. Seis anos mais tarde, definiu-se a Lei 633, que diz respeito às taxas de licenças ambientais. Por meio delas, as autoridades ambientais cobram a avaliação de serviços e monitoramento da licença ambiental, autorizações, concessões e outros instrumentos estabelecidos para controle ambiental (Vasconcelos, 2011).

Os atos administrativos, as resoluções, as circulares e outros, por parte das diversas autoridades administrativas, permanecem válidos, com base nos poderes derivados dos decretos compilados. Não há, no 
entanto, uma normatização específica para o meio empresarial acerca da evidência de informações sociais relacionadas a suas atividades.

A ciência contábil representa uma base importante para que estudos ambientais sejam desenvolvidos a contento no âmbito dos negócios, na medida em que os efeitos econômicos imputados ao patrimônio devem ser bem interpretados para que a informação seja útil na tomada de decisão.

Atualmente, as empresas estão mais dispostas a participar da discussão ambiental por reconhecer a necessidade, a urgência e o diferencial positivo na sua imagem no mercado (Gonçalves, 2012). Apresentar relatórios sociais, portanto, é um fator de competitividade que deixa a empresa à frente de concorrentes que ainda não o fazem (Dowbor, Sachs \& Lopes, 2010).

A partir do momento em que problemas relacionados ao meio ambiente começaram a surgir nas empresas, "os gestores passaram a requerer da contabilidade informações financeiras que os ajudassem nesse trabalho e para as quais os contadores, de modo geral, não se encontravam (encontram) preparados" (Ferreira, 2011, p. 53).

Diante desse cenário, fez-se necessária a atualização dos profissionais dessa área, quanto aos assuntos relacionados ao meio ambiente e do que se tratava essa nova contabilidade, que, até então, poucos tinham acesso.

Portanto, a contabilidade socioambiental tem papel fundamental na motivação, na identificação, na orientação, na formulação e na divulgação de relatórios compostos por informações sociais relacionadas às atividades das empresas, de forma que sejam transmitidas formalmente, com transparência e confiabilidade, como direcionam os princípios contábeis existentes para toda demonstração contábil elaborada (Alvarez \& Mota, 2010).

\section{Metodologia}

Quanto à abordagem adotada, foi desenvolvida uma pesquisa qualitativa com o objetivo de realizar um estudo mais aprofundado sobre o tema escolhido. No que se refere aos objetivos, foi realizada uma 
pesquisa exploratória devido à necessidade de examinar informações complementares a fim de ampliar o conhecimento sobre o tema abordado. Paralelamente, utilizou-se da pesquisa descritiva com o intuito de delinear as características do problema em questão.

Como procedimento adotado durante a coleta de dados, foi utilizada a pesquisa bibliográfica a partir de material impresso e virtual, em especial, oriundos de livros e periódicos especializados, bem como de relatórios, documentos e legislação disponíveis, o que caracteriza a pesquisa como documental. Como técnica de exame, foi utilizada a análise de conteúdo do material bibliográfico selecionado com vistas a estabelecer uma relação entre o material e os objetivos do trabalho (Gil, 2014).

Foi analisado o relatório de sustentabilidade de 2014 da empresa colombiana Ecopetrol a fim de compará-lo com a normatização brasileira para avaliá-lo perante as informações requeridas pela NBC T 15 , uma vez que esta mostra como ele deve ser elaborado. A primeira etapa foi identificar no relatório ambiental da Ecopetrol os itens abordados conforme a norma brasileira requer. Em seguida, uma análise do conteúdo foi realizada para descrever criticamente acerca das informações divulgadas.

\section{Resultados e discussão}

A Ecopetrol atua no setor de petróleo e gás integrado há 63 anos, e é a maior empresa na Colômbia que atua nessa área. Ainda, está envolvida em todos os elos da cadeia de exploração de hidrocarbonetos, produção, comercialização e transformação de combustíveis e produtos de maior valor agregado, como petroquímicos.

No que concerne ao status legal, a Ecopetrol é uma empresa mista, comercial, organizada como uma corporação, no âmbito nacional, vinculada ao Ministério de Minas e Energia, em conformidade com as disposições da Lei 1.118 de 2006, regida pelo Estatuto Social presente no documento de n. $^{\circ} 5.314$ de 14 de dezembro de 2007, emitido pela Notaria Segunda do Distrito Notarial de Bogotá (equivale ao Contrato Social brasileiro). 
Seus campos de extração estão localizados no centro, sul, leste e norte da Colômbia. Essa empresa tem duas refinarias (Barrancabermeja e Cartagena) e três portos de exportação e importação de combustíveis e matérias-primas em ambas as costas (Coveñas e Cartagena, no mar do Caribe, e Tumaco, no oceano Pacífico). Também é de sua propriedade a maioria do petróleo e de oleodutos que ligam sistemas de produção com grandes centros de consumo e terminais marítimos do país. Além disso, é acionista em outras empresas dos setores de exploração e produção, transporte, refinaria e petroquímica e biocombustíveis.

No que diz respeito ao negócio de biocombustíveis, nos últimos anos, a Ecopetrol tem investido internacionalmente e já está presente no Brasil, no Peru e nos Estados Unidos (Golfo do México). Em 2011, entrou no Índice de Sustentabilidade Dow Jones e atingiu o nível bronze nos dois anos seguintes. No ano de 2014, a empresa colombiana continuou destacando-se e recebeu vários prêmios e reconhecimentos voltados para a área de sustentabilidade ambiental e responsabilidade corporativa.

A normatização da Colômbia que trata das questões ambientais é bastante ampla, o que leva as empresas a elaborarem os relatórios com as ações que competem à questão social e ambiental à sua maneira. Em compensação, a NBC é mais objetiva e específica ao demonstrar o que é necessário estar disposto em um relatório ambiental, seja ele um balanço social, seja um relatório de sustentabilidade. Assim, a análise do relatório, item a item, deu-se conforme a estrutura fornecida pela norma brasileira.

O item 15.1 da NBC T 15 traz o conceito e os objetivos da norma. Nesse item, consta o que deverá ser apresentado no relatório contábil e quais as informações que serão tratadas como informações de natureza social e ambiental. Comparando com o relatório de sustentabilidade, verificou-se que este está de acordo com o que é proposto na norma contábil brasileira.

De acordo com a Ecopetrol, a Controladoria-geral da Nação (CGN, equivale ao Conselho Federal de Contabilidade no Brasil) adotou o Sistema de Contabilidade Pública (SCP) em setembro de 2007 quando declarou sua conformação e definiu seu escopo. Na comunicação n. ${ }^{\circ}$ 
20079-101345 de 28 de setembro do mesmo ano, emitido pela CGN, ordenou-se a aplicação do SCP na empresa a partir de $1^{\circ}$ janeiro de 2008.

A respeito das normas ambientais, a Ecopetrol suporta as pesquisas de seus impactos ambientais em uma linha estratégica cujo objetivo é contribuir com a mitigação dos efeitos negativos de sua produção no país. Além da conformidade regulamentar das operações e de ser a base para a sustentabilidade empresarial, adotam programas e projetos que visam: minimizar a geração de emissões atmosféricas; reduzir o consumo de água e geração de descarga; aplicar a gestão integral de resíduos; conservar a biodiversidade, preservá-la e utilizá-la de forma sustentável, e gerar padrões de ecoeficiência. Tal comportamento contribui para o cumprimento das metas estabelecidas no Plano de Desenvolvimento Nacional sobre as questões ambientais.

No item 15.2, estão dispostas as informações que serão divulgadas no relatório. Está dividido em quatro subitens. Referente ao item 15.2.1, que trata da geração e distribuição de riquezas, a norma informa que "a riqueza gerada e distribuída pela entidade deve ser apresentada conforme a Demonstração do Valor Adicionado (DVA)". O relatório não apresenta dados dessa natureza, como se pede na norma brasileira.

O item 15.2.2 trata dos recursos humanos, cujo relatório da empresa em estudo apresenta apenas alguns dos dados requeridos e deixa algumas informações relevantes sem registro, como o número de funcionários divididos, etnia e nível de escolaridade, disponibilizando apenas a informação que mostra a distribuição dos funcionários por sexo biológico e faixa etária, apresentados em gráfico. No relatório, constam as informações em números sobre a segurança social, benefícios, saúde, educação, contribuições fiscais e outros. Em relação aos benefícios, as informações são genéricas, isto é, não há discriminação que especifique os gastos.

Os dados fornecidos pelo relatório de sustentabilidade, referentes a sociedade e comunidade, estão dispostos em modelo de metas da empresa, e não em valores gastos. Assim, a mensuração quantitativa desses quesitos fica comprometida devido à falta de objetividade e clareza dos dados divulgados.

Uma vez que consta apenas o valor gasto com funcionários, mas não está especificado quanto desse valor foi para salários ou para outros 
gastos referentes aos funcionários, como alimentação, auxílio-creche, transportes, capacitação de pessoal e outros fatores requeridos pela NBC T 15, verificou-se que, nesse item, as informações disponibilizadas pela Ecopetrol são limitadas.

No item 15.2.3, que é o item que trata da interação da entidade com o ambiente externo, a empresa Ecopetrol divulga metas estabelecidas para o ano de 2014 com ações relacionadas à sociedade e à comunidade. No entanto, a empresa apenas as divulga, não estipula valores a serem investidos, o que impossibilita o leitor de identificar quanto a empresa está disposta a investir nas ações citadas. Além disso, não há como mensurar a representatividade dessas metas com relação ao faturamento ou à produtividade anual da empresa. Não havendo parâmetros, a avaliação do item fica insuficiente.

Referente ao item que trata dos fornecedores, o relatório da Ecopetrol demonstra que há $100 \%$ de satisfação, porém, na NBC T 15, outros itens são citados, como o número de reclamações recebidas diretamente na entidade pelos órgãos de fiscalização e pela justiça, e os valores de multas e indenizações a clientes. Não ter esse registro discriminado no relatório da empresa faz com que as informações relacionadas a isso não sejam demonstradas de forma clara.

O item 15.2.4 requer informações relativas à interação com o meio ambiente. $\mathrm{O}$ relatório divulga valores e dados relevantes, mas parte das informações se repetem em outros itens. A norma brasileira estabelece que os dados fornecidos pela empresa devem estar de acordo com os itens, e cada item está dividido em interações da empresa com diferentes ramos.

A empresa disponibilizou algumas informações pertinentes, porém se constataram mais informações referentes aos objetivos e às metas da empresa do que valores efetivamente gastos com essas ações. Assim, as informações disponibilizadas são genéricas e propiciam às partes interessadas um entendimento tendencioso. A empresa preocupa-se em demonstrar informações que acreditam poder agradar mais aos usuários ao invés de promover a transparência de suas práticas, $\mathrm{o}$ que evidencia pontos fortes e fracos na mesma magnitude.

O próximo item, o 15.3, traz as disposições finais que tratam das informações ainda não requeridas nos itens anteriores. A Ecopetrol 
disponibiliza, nesse ponto, diversas informações subjetivas e dispostas de forma aleatória. Dados relacionados a metas traçadas e cumpridas, que seguem o padrão das demais informações analisadas. Algumas dessas informações se referem a metas contidas no Pacto Global com relação aos direitos humanos, ao meio ambiente e à corrupção, e, ain$\mathrm{da}$, alguns resultados financeiros da empresa.

\section{Conclusões}

Atendendo ao objetivo principal de avaliar o relatório social da Ecopetrol com base nos itens propostos pela NBC T 15, verificou-se que as informações foram transmitidas subjetivamente pela empresa, o que possibilita interpretações variadas.

O decreto que normatiza os relatórios sociais na Colômbia é muito abrangente e pouco conciso quanto ao tipo das informações e à apresentação delas, fazendo com que os relatórios sejam mais subjetivos em suas informações, diferentemente da norma brasileira. No entanto, isso não garante que as empresas cumpram com o requerido, uma vez que a NBC T 15 não possui penalizações para o seu possível descumprimento.

O relatório da empresa selecionada atende parcialmente aos quesitos requeridos pela NBC T 15 , mesmo sendo uma organização colombiana com normas diferenciadas e menos exigentes quanto ao detalhamento das informações. No entendimento atual do mercado global, porém, vale ressaltar que as empresas devem promover ações em todas as instâncias administrativas e operacionais com vistas à pluralidade das exigências e dos padrões internacionais. Assim, a Ecopetrol está um passo à frente com relação à normatização dos relatórios sociais em seu país. Este trabalho identificou pontos que podem trazer mais melhorias nessa questão.

Partindo da informação de que as questões socioambientais são globais, faz-se necessário um esforço coletivo mais concentrado em auxiliar as empresas a elaborarem tais demonstrações, publicando suas práticas socialmente responsáveis de forma efetiva. Os relatórios devem evidenciar, além de números absolutos, dados de itens específicos 
bem como métodos utilizados, comparativos históricos, resultados alcançados e informações que aparentemente podem ser consideradas negativas, mas que demonstram a preocupação da empresa com a transparência de suas atividades, como número de acidentes e processos trabalhistas do período, por exemplo.

A contabilidade socioambiental nesse contexto tem uma função norteadora que fornece embasamento para maior conhecimento e compreensão dos dados a serem divulgados. Nesse interim, profissionais contábeis especialistas da área exercem papel relevante na compilação e no tratamento de informações, bem como na conscientização da equipe de trabalho que exerce ou pode exercer práticas socialmente responsáveis na empresa.

A necessidade de se ter uma norma norteadora global para tais relatórios empresariais é emergencial. A contabilidade socioambiental configura-se como uma ferramenta de fundamental relevância na compreensão e na aplicação das práticas de responsabilidade social empresarial. Além disso, pode servir de auxílio especializado à construção de políticas públicas com vistas ao bem-estar social, econômico e ambiental das gerações presentes e futuras, como objetiva o conceito do desenvolvimento sustentável.

Esta pesquisa mostrou a necessidade e a importância dos relatórios sociais bem estruturados, que zelem pela transparência e pela comunicação com seus usuários. Recomenda-se que os profissionais colombianos da contabilidade socioambiental, em conjunto com o meio público e empresarial, busquem padronizar tais publicações. Normatizações específicas, que visem à participação de todas as partes interessadas, demonstram a efetivação com o compromisso que toda a humanidade possui em preservar e conservar o meio ambiente com atividades sustentáveis e socialmente responsáveis. 


\section{Referências}

ABNT (Associação Brasileira de Normas Técnicas). (2010). ABNT NBR ISO 26000: Diretrizes sobre Responsabilidade Social. Rio de Janeiro: ABNT.

ABNT (Associação Brasileira de Normas Técnicas). (2012). ABNT NBR 16001: responsabilidade social — sistema de gestão — requisitos. Rio de JaneirO: ABNT.

Alvarez, R. A. \& Mota, J. A. (orgs.). (2010). Sustentabilidade ambiental no Brasil: biodiversidade, economia e bem-estar humano. Brasília: Ipea.

Becchetti, L., Ciciretti, R., Hasan, I. \& Kobeissi, N. (2012). Corporate social responsibility and shareholder's value. Journal of Business Research, 65, 1628-1635.

Beets, S. \& Souther, C. C. (1999). Corporate environmental reports: the need for standarts and an environmental assurance service. Account horizons, 13(2), 129-145.

Bovespa. Bolsa de Valores de São Paulo. (2015). Índice de sustentabilidade empresarial. Recuperado de http://www.bmfbovespa.com.br/pt_br/produtos/indices/indices-de-sustentabilidade/indice-de-sustentabilidade-empresarial-ise.htm.

Carvalho, F. M. \& Siqueira, J. R. M. (2012). Regulamentações brasileiras do balanço social. Em A. C. S. Ferreira, J. R. M. Siqueira \& M. Z. Gomes (orgs.), Contabilidade ambiental e relatórios sociais. 2. ed. (pp. 23-41). São Paulo: Atlas.

CFC [Conselho Federal de Contabilidade] (2004). Resolução CFC $n$ ' $^{\circ}$ 1.003/04. NBC T 15 - Informações de natureza social e ambiental. Recuperado de http://www2.cfc.org.br/sisweb/sre/detalhes_sre. aspx?Codigo=2004/001003

Colômbia. (1999). Código de Recursos Naturales. Recuperado de http://faolex.fao.org/cgibin/faolex.exe?rec_id=150098\&database=faolex\&search_type=link \&table=result $\&$ lang=spa\&format_name=@SRAL

Colômbia. (1991). Nueva Constitución Política de Colombia 1991. Recuperado de http://faolex.fao.org/cgibin/faolex.exe?rec_id=150098\&database=faolex\&search_type=link\&table=result\&lang=spa\&format_name=@SRAL

Colômbia. (1994). Decreto n. ${ }^{\circ} 1753$ de 26 de maio de 1994. Recuperado de http://faolex.fao.org/cgibin/faolex.exe?rec_id=150098\&database=faole$\mathrm{x} \&$ search_type=link\&table=result\&lang=spa\&format_name=@SRALL 
Colômbia. (2004). Norma técnica colombiana NTC-ISO 14001. Recuperado de https://gestionambientalempresarial.wordpress.com/.../norma-tecnica-

Colômbia. (1993). Ley General Ambiental de Colombia. Ley n. 99 de 1993. Recuperado de https://www.google.com.co/\#q=Ley+99+de+1993

CMMAD/WCED [Comissão Mundial para o Meio Ambiente/World Commission on Environment and Development] (1987). Our Common Future. Oxford: Oxford University Press.

CVM [Comissão de Valores Mobiliários]. (2016). Pareceres de Orientação. Recuperado de http://www.cvm.gov.br

Dowbor, L., Sachs, I. \& Lopes, C. (orgs.). (2010). Riscos e oportunidades: em tempos de mudanças. São Paulo: Editora e Livraria Instituto Paulo Freire; Fortaleza, CE: Banco do Nordeste do Brasil.

Ecopetrol (2015). Reporte Integrado de Gestión Sostenible 2014. Recuperado de http://julibe.com/work/ecopetrol/reporte-2014/espanol/superior/ reporte-integrado-de-gestion-sostenible-2014/sobre-este-reporte/

Eon, F. (2015). O que é responsabilidade social? Revista Responsabilidade Social.com. Recuperado de http://www.responsabilidadesocial. com/o-que-e-responsabilidade-social/

Ferreira, A. C. S. (2011). Contabilidade ambiental: uma informação para o desenvolvimento sustentável. São Paulo: Atlas.

Gil, A. C. (2014). Métodos e técnicas de pesquisa social. 6. ed. São Paulo: Atlas.

Gonçalves, C. F. (2012). Pegada de carbono no ciclo de vida da celulose de eucalipto (Dissertação de mestrado em desenvolvimento regional e meio ambiente). Universidade Estadual de Santa Cruz (UESC), Ilhéus, Bahia.

Ibase [Instituto Brasileiro de Análise Social e Econômica]. (2016). Responsabilidade social das empresas. Recuperado de http://www.ibase.org.br

Siqueira, J. R. M. \& Vidal, M. C. R. (2002). Balanços sociais brasileiros: uma análise crítica das publicações do ano de 2001. Em Seminário usp de Contabilidade, 2. São Paulo. Anais eletrônicos. Recuperado de http:// www.eac.fea.usp.br/congressousp/seminario2/index.htm

Torres, C. (2001). Responsabilidade social das empresas (RSE) e balanço social no Brasil. Em C. A. T. Silva \& F. S. Freire (orgs.). Balanço social: teoria e prática. São Paulo: Atlas.

Vasconcelos, M. A. L. (2011). Harmonização de legislação ambiental no Mercosul: a adoção de políticas comuns como fator de conservação do meio ambiente. Brasília: edição do autor. 
Sección I. Responsabilidad Social Empresarial (RSE)

Vellani, C. L. (2011). Contabilidade e responsabilidade social: integrando desempenho econômico, social e ecológico. São Paulo: Atlas.

Vieira, M. T. \& Faria, A. C. (2007). Aplicação da NBC T 15 por empresas dos segmentos de bebidas e alimentos: uma pesquisa documental. Revista Universo Contábil, 3(1), 49-69. 
